\title{
Pemanfaatan Limbah Sampah Plastik Menggunakan Metode Ecobrick di Desa Luwuk Kanan
}

\author{
Ridha Nirmalasari ${ }^{1}$, Ahmad Ari Khomsani ${ }^{1}$, Dhea Nur'aini Rahayu ${ }^{1}$, Lidia ${ }^{1}$, Maulida Rahayu ${ }^{1}$, \\ Meliyani Syahrudin ${ }^{*}$, M. Rezqi Anwar ${ }^{1}$, Rahmatul Jennah$^{1}$, Salma Syafiyah ${ }^{1}$, Suriadi', Yoga \\ Setiawan $^{1}$
}

${ }^{1}$ Institut Agama Islam Negeri Palangka Raya, Jalan G. Obos IX, Palangka Raya, Kalimantan Tengah, Indonesia, 74874

*Email koresponden: melispt2017@gmail.com

\section{ARTICLE INFO}

Article history

Received: 22 Nov 2021

Accepted: 21 Des 2021

Published: 31 Des 2021

\section{Kata kunci:}

Desa Luwuk Kanan;

Ecobrick;

Limbah sampah;

\section{Keyword:}

Ecobricks;

Garbage waste;

Luwuk Kanan village;

\section{A B S T R A K}

Background: Plastik merupakan sampah non organik yang memiliki banyak manfaat terutama dalam kehidupan sehari-hari, utamanya para penjual di pasaran dalam pengemasan makanan, bahan dasar pembuatan komponen otomotif dan dapat digunakan sebagai bahan dasar pembuatan mainan. Banyaknya plastik yang digunakan oleh masyarakat dan dibuang begitu saja setelah dipakai maka akan menyebabkan timbulnya sampah. Pelakasanaan Program pengabdian ini dimaksudkan agar warga bisa memanfaatkan sampah untuk menghasilkan barang-barang yang bernilai ekonomis. Desa Luwuk Kanan merupakan desa yang memiliki presentase penduduk yang besar, dari banyaknya jumlah penduduk mengakibatkan munculnya persoalan mengenai penanggulangan sampah, selama ini masyarakat menanggulangi sampah di desa tersebut dengan cara dibakar dan tidak sedikit pula yang membuangnya ke aliran sungai Katingan, hal inilah yang mengakibatkan pendangkalan sungai yang berakibat terjadinya banjir. didasarkan masalah tersebut, Ecobrick dapat menjadi solusi pengurangan dan pemanfaatan sampah plastik menjadi produk bernilai ekonomis. Metode: PAR (Participatory Action Research) yaitu pengabdian berbasis masalah yang ditemukan lalu kemudian memberikan alternative solusi. Hasil: Pemanfaatan limbah plastik di Desa Luwuk Kanan dengan metode Ecobrik. Ecobrick salah satu metode dari Recycle, yang merupakan sebutan untuk botol plastik yang diisi dengan bahan non-organik hingga menjadi sangat padat dan keras. Kesimpulan: Diperkenalkannya metode ecobrik kini masyarakat dapat mengolah sampah menjadi bahan yang bernilai ekonomis dan ramah lingkungan.

\section{A B S T R A C T}

Background: Plastic is a non-organic waste that has many benefits, especially in everyday life, especially sellers in the market in food packaging, basic materials for making automotive components, and can be used as a primary material for making toys. The amount of plastic used by the community and thrown away after use will cause the emergence of waste. This devotion program is intended so that citizens can use waste to produce goods of economic value. Luwuk Kanan village is a village that has a large percentage of the population, from the large number of residents resulting in the emergence of problems regarding waste management, so far the community copes with garbage in the village by burning and not a few who throw it into the katingan river stream, this is what causes river siltation that results in flooding. Based on these problems, Ecobrick can be a solution to reduce and utilize plastic waste into economically valuable products. Method: PAR (Participatory Action Research) is a problem-based devotion that is found and then provides alternative solutions. Results: Utilization of plastic waste in Luwuk Kanan Village with Ecobrik method. Ecobrick is one of the recycling methods, which is a term for plastic bottles filled with non-organic materials until they become very dense and complex. Conclusion: The introduction of 
ecobric methods can now process waste into materials of economic value and environmentally friendly.

(c) 2021 by authors. Lisensi Jurnal Solma, UHAMKA, Jakarta. Artikel ini bersifat open access yang didistribusikan di bawah syarat dan ketentuan Creative Commons Attribution (CC-BY) license.

\section{PENDAHULUAN}

Plastik merupakan sampah non organik yang memiliki banyak manfaat namun juga memiliki dampak negatif yang besar bila tidak di manfaatkan dan dipergunakan dengan baik terutama dalam kehidupan sehari-hari. Dewasa ini, meningkatnya penggunaan plastik pada kehidupan sehari-hari dikhawatirkan memiliki dampak yang buruk karena plastik merupakan sampah non organik yang sulit terurai (Putra \& Yuriandala, 2010). Plastik sering dimanfaatkan oleh masyarakat utamanya para penjual di pasaran diantaranya dalam pengemasan makanan, bahan dasar pembuatan komponen otomotif serta juga dapat dibuat sebagai bahan dasar pembuatan mainan anak-anak dan masih banyak hal lainnya yang terbuat dari bahan tersebut. Banyaknya plastik yang digunakan oleh masyarakat dan dibuang begitu saja setelah dipakai maka akan menyebabkan timbulnya pencemaran lingkungan (Indaraswati, 2017).

Sampah plastik merupakan barang bekas yang tidak digunakan dan materialnya terproduksi dari bahan kimia yang tak terbarukan. Menurut Jambeck et al., (2015); Nufus \& Zuriat, (2020) Indonesia merupakan Negara dengan posisi kedua di dunia setelah China yang merupakan penghasil sampah plastik di perairan sekitar 187,2 juta ton. Dibuktikan dengan data dari Kementrian Lingkungan Hidup dan Kehutanan yang menyebutkan bahwa sampah plastik hasil dari 100 toko ataupun anggota Asosiasi Pengusaha Ritel Indonesia (APRINDO) dalam waktu satu tahun dapat mencapai sekitar 10,95 juta lembar sampah kantong plastik. Jumlah ini ternyata sama dengan luasnya 65,7 hektar kantong plastik (Purwaningrum, 2016).

Plastik terbuat dari zat-zat petrokimia yang sangat berbahaya jika kembali lagi ke lingkungan. Penelitian menunjukkan adanya zat-zat kimia tersebut berbahaya bagi kehidupan khususnya manusia (Nuruzzaman, 2021). Pembakaran sampah plastik dapat memicu gas-gas beracun seperti karbon monoksida $(\mathrm{CO})$ dan hidrogen sianida $(\mathrm{HCN})$. Plastik yang dibakar, berceceran, atau dibuang terurai menjadi zat-zat kimia beracun sehingga zat-zat tersebut akan larut ke tanah, air, dan udara. Jika mencapai ke lingkungan makhluk hidup maka dapat menyebabkan kecacatan lahir, terganggunya hormon, dan kanker. Bahkan, tempat penampungan sampah yang canggih sekalipun bukanlah solusi yang baik karena zat-zat kimia tersebut akan tetap meresap ke dalam biosfer atau kehidupan makhluk hidup disekitar, khususnya sangat berdampak pada kelangsungan hidup manusia (Istirokhatun \& Nugraha, 2019).

Meningkatnya sampah plastik dan juga bahayanya bagi lingkungan maka akan menjadi problematika yang serius jika solusi untuk mengatasinya tidak ditemukan (Fauzi et al., 2019). Konsep 3R dirasa dapat menjadi solusi dalam menangani sampah plastik. pengelolaan sampah menggunakan gaya baru $3 \mathrm{R}$ ialah model yang sangat awam dalam memberikan prioritas yang teratas dalam mengelola limbah dapat beoriensasi dalam mencegah muncunculnya sampah, meminimalisasi sampah menggunakan cara barang yang sudah tak digunakan supaya dapat digunakan lagi. serta limbah yang bisa didaur ulang dengan metode biodegradeable (biologi) juga cara membuang limbah dengan metode ramah lingkingan (Rosita \& Mintarsih, 2021). 
Konsep 3R dapat dilakukan dengan cara: Reuse yang berarti menggunakan kembali barangbarang yang terbuat dari bahan plastik, Reduce yang berarti mengurangi pembelian atau pemakaian barang-barang dari bahan plastik, terutama barang-barang yang sekali pakai dan Recycle yaitu mendaur ulang barang-barang yang terbuat dari bahan plastik. Maka dari konsep di atas beberapa penelitian telah dilakukan untuk memanfaatkan kembali plastik yang tidak terpakai dan yang telah dibuang ke lingkungan. Dalam hal ini menggunakan salah satu konsep 3R yaitu Recycle yang berarti melakukan daur ulang terhadap sampah plastik.

Desa Luwuk Kanan merupakan desa yang terletak di pinggir sungai, sehingga limbah masyarakat pada umumnya diangkut menggunakan perahu kayu melewati sungai menuju ke tempat pembuangan akhir (TPA) yang berada di desa seberang. Jenis sampah yang dihasilkan oleh masyarakat desa luwuk kanan dominan merupakan sampah plastik atau anorganik. Banyaknya produksi sampah anorganik menjadi salah satu permasalahan yang memerlukan penanganan yang lebih serius utamanya dalam proses pengangkutan menuju ke TPA.

Menghadapi masalah sampah, daur ulang limbah sampah plastik merupakan solusi terbaik dalam mengatasinya, apabila masyarakat belum mampu untuk mengelola sampah. Maka salah satu daur ulang limbah yang dapat dilakukan ialah mendaur ulang botol plastik melalui ecobrick. Ecobrick adalah teknik pengolahan sampah plastik yang dirubah menjadi material ramah lingkungan atau disebut juga bata yang ramah lingkungan. Dalam pembuatan ecobrick sangatlah simple dan mudah, cukup dengan memasukkan plastik-plastik bekas kedalam botol plastik bekas hingga padat dan telah menjadi keras. Fungsi dari ecobrick bukan hanya untuk menghancurkan sampah plastik akan tetapi untuk memperpanjang usia plastik-plastik tersebut menjadi sesuatu yang sangat berguna untuk kebutuhan manusia (Zuhri et al., 2020).

\section{MASALAH}

Desa Luwuk Kanan merupakan salah satu lokasi target pengabdian tim dari IAIN Palangka Raya yang berlokasi di Kecamatan Tasik Payawan, Kabupaten Katingan. Penduduk desa Luwuk Kanan berjumlah 1791 jiwa, dengan jumlah kepala keluarga 535 KK. Adapun wilayah administrasi desa Luwuk Kanan terdiri dari 9 RT dan 2 RW. Secara geografis Desa Luwuk Kanan terletak di wilayah utara kabupaten Katingan dengan luas wilayah kurang lebih 13000 Hektar. Desa merupakan tempat bermukimnya para masyarakat yang melakukan kegiatan sehari-hari. Timbulnya masalah sampah dimulai dari limbah rumah tangga. Mengenai potensi masalah sampah yang dihadapi Desa Luwuk Kanan ialah sampah dibuang di sungai bahkan dibuang di pinggir jalan, dan dibiarkan menumpuk. Kurangnya koordinasi tentang tempat pembuangan akhir sampah atau tidak adanya bank sampah di desa tersebut juga menjadi salah satu masalah di desa Luwuk Kanan. Sehingga kebanyakan masyarakatnya lebih memilih untuk mengatasinya dengan cara membakar. Akan tetapi, membakar sampah bukanlah solusi yang efektif untuk menghilangkan sampah. Malah sebaliknya, menambah masalah terhadap lingkungan sekitar.

Berdasarkan pada hasil observasi yang dilaksanakan di Desa Luwuk Kanan, Kecamatan Tasik Payawan, Kabupaten Katingan diperoleh suatu permasalahan diantaranya ialah tidak adanya pemanfaatan sampah khususnya pada limbah sampah plastik. Selama ini sampah tersebut hanya sebatas tumpukan material yang tidak memiliki nilai manfaat. Maka berdasarkan hal tersebut muncullah solusi untuk mengoptimalkan pemanfaatan sampah anorganik melalui 
pemanfaatan limbah sampah plastik dengan menggunakan metode ecobrick. Solusi ini diharapkan mampu menumbuhkan budaya mencintai lingkungan dengan cara lebih menjaga lingkungan demi terciptanya suatu lingkungan yang sehat dan bersih dan serta juga dapat menjadi produk yang bernilai ekonomis melalui pemanfaatan sampah menjadi produk Ecobrick.

\section{METODE PELAKSANAAN}

\section{Sasaran Kegiatan}

Sasaran kegiatan pengabdian ini adalah masyarakat di desa Luwuk Kanan Kecamatan Tasik Payawan, Kabupaten Katingan, Provinsi Kalimantan Tengah. Pembuatan Ecobrick secara rutin dapat dilakukan oleh masyarakat sebagai upaya dalam penanggulangan sampah plastik. Target kegiatan ini adalah limbah plastik di Desa Luwuk Kanan yang dimanfaatkan dengan menggunakan metode ecobrick menjadi barang-barang yang bermanfaat dan bernilai ekonomis.

\section{Lokasi Kegiatan}

Kegiatan pembuatan ecobrick dilaksanakan pada tanggal 21-30 agustus 2021 di desa Luwuk Kanan, Kecamatan Tasik Payawan, Kabupaten Katingan, Provinsi Kalimantan Tengah.

\section{Metode Kegiatan}

Kegiatan pengabdian kepada masyarakat ini dilakukan dengan menggunakan metode PAR dengan cara 5T (To Know, To Understand, To Plan, To Action, To Reflection). Metode ini juga digunakan untuk mengidentifikasi masalah yang ada pada masyarakat dan kemudian memecahkan masalah tersebut (Problem Solving). Adapun masalah yang terdapat di lingkungan tersebut ialah masih minimnya kesadaran masyarakat terkait pengelolaan sampah dan banyak dari masyarakat membuang sampah ke sungai sehingga dapat menimbulkan pencemaran. Metode Ecobriks dirasa dapat menjadi solusi untuk permasalahan sampah tersebut.

\section{HASIL DAN PEMBAHASAN}

Pengelolaan sampah yang masih belum maksimal merupakan salah satu masalah besar di desa ini, khususnya sampah yang berbahan plastik yang sifatnya yang sulit terurai di alam, serta di desa Luwuk Kanan belum terdapat industri daur ulang sampah. Sehingga menyebabkan kurangnya kesadaran masyarakat terhadap lingkungan hal ini dibuktikan dengan seringnya warga membuang sampah ke sungai, lahan kosong, bahkan di pinggir jalan. Namun, secara sederhananya masyarakat mengolah sampah plastik dengan cara di bakar, hal tersebut akan menyebabkan terlepasnya gas-gas beracun ke udara.

Permasalahan sampah plastik yang banyak ditemukan di lingkungan tersebut, maka akan berpotensi untuk mencemari lingkungan sekitarnya. Plastik terbuat dari petro-kimia dan termasuk bahan yang mengandung photodegrade yang berarti plastik secara perlahan-lahan akan pecah menjadi potongan-potongan kecil kemudian akan menyerap ke dalam tanah dan air. Mereka yang diserap oleh tanaman dan hewan pada akhirnya juga akan diserap oleh manusia. Sampah plastik yang berserakan, dibakar atau dibuang akan menghasilkan bahan kimia beracun (Andriastuti et al., 2019). Plastik harus dihilangkan ataupun diolah sebaik-baik mungkin untuk mencegah hal-hal yang merugikan untuk kehidupan. 
Metode pengelolaan sampah dengan Reduce, Reuse, dan Recycle, dilakukan untuk mengunci sampah plastik yang tidak terdegrasi. Saat ini banyak aktivis pencinta lingkungan yang menjaga kelestarian alam, dengan mengolah limbah plastik. Saat ini telah ditemukan salah satu upaya untuk memanfaatkan limbah sampah plastik dengan metode baru yang di sebut dengan ecobrick (Sumastuti et al., 2018). Oleh karena itu pembuatan ecobrick ini merupakan solusi mudah untuk mengatasi masalah sampah plastik yang terdapat di Desa Luwuk Kanan dan juga dapat menjadikannya sebagai produk yang bernilai.

Ecobrick salah satu metode dari Recycle, yang merupakan salah satu cara daur ulang untuk botol plastik yang berisi bahan non-organik hingga menjadi sangat padat dan keras (Ikhsan \& Tonra, 2021). Ecobrick dibuat dengan memanfaatkan botol plastik bekas yang terdiri dari sampah kantong plastik, pembungkus makanan ataupun bahan plastik lainnya, yang dipotong kecil-kecil. Produk Ecobrick ini dapat dimanfaatkan menjadi bahan bangunan, furniture seperti meja, kursi, bangunan serta taman dalam jumlah yang banyak seperti rumah dan sekolah. Ecobrick juga merupakan keterampilan dalam bidang seni yang mana mendaur ulang sampah plastik yang menghasilkan karya ramah lingkungan (Palupi et al., 2020).

Pembuatan ecobrick pada dasarnya tidak membutuhkan keterampilan yang khusus, dan tanpa biaya apapun karena semua barang yang dibutuhkan berasal dari barang-barang bekas yang dikonsumsi sehari-hari (Rahayu, 2021). Barang-barang bekas tersebut berupa sampah plastik dari rumah tangga. Pembuatannya juga bisa dikerjakan kapan saja, dan bisa juga dikerjakan secara individu ataupun berkelompok sembari mengisi waktu luang. Maka, pembuatan ecobrick ini tidaklah sulit, hanya saja membutuhkan ketekunan dan sedikit usaha. Dalam pembuatan ecobrick ini ada hal yang harus dipikirkan yaitu sampah plastik yang diperoleh-dikumpulkan, kemudian dibersihkan dan dikeringkan agar tidak menimbulkan bau busuk yang tersimpan di dalam botol ecobrick.

Pengabdian ini dilakukan dengan menggunakan metode PAR dengan cara 5T (To Know, To Understand, To Plan, To Action, To Reflection). To Know, memberikan gambaran pada masyarakat tentang sampah, jenis sampah, dan cara penanggulangan sampah. To Understand, memberikan pemahaman pada masyarakat tentang jenis-jenis sampah, dan penanganan terhadap setiap jenis sampah (anorganik dan organik). To Plan, berdiskusi dengan masyarakat setempat terkait penanganan sampah khususnya sampah anorganik, sehingga pemilihan metode ecobrik menjadi solusi yang tepat terhadap penanganan sampah anorganik di desa Luwuk Kanan. To Action, bersama masyarakat mengumpulkan sampah organik atau sampah plastik kemudian diolah menggunakan metode Ecobrick. To Reflection, hasil pembuatan ecobrick diberikan pada masyarakat melalui aparat desa Luwuk Kanan untuk dimanfaatkan antara lain sebagai hiasan, alas duduk, meja dan sebagainya.

Adapun tahap-tahap pembuatan ecobrick yaitu:

1. Siapkan botol bekas (botol haruslah bersih dan kering baik itu ukuran 1,5 L atau $600 \mathrm{ML}$ ) 


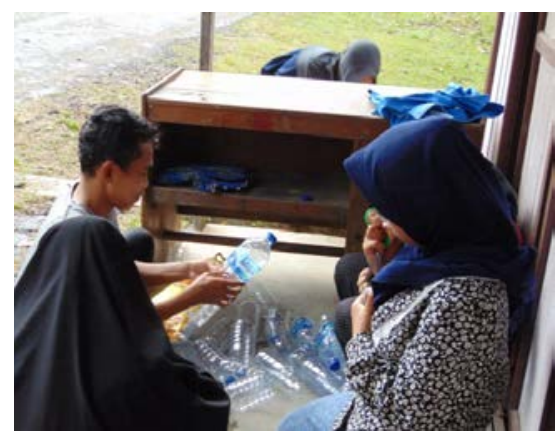

Gambar 1.

Proses Persiapan Pengumpulan Botol Bekas

2. Dalam pembuatan ecobrick Bahan utama yang harus tersedia adalah sampah plastik. segala macam sampah plastik bisa digunakan dalam pembuatan ecobrick ini, seperti kemasan sampah minuman, kemasan deterjen, kresek (katong plastik), bisa juga bungkus-bungkus makanan ringan, dan lain-lain. Setelah sampah plastik yang terkumpulkan, maka bersihkanlah sampah tersebut dengan mencucinya.
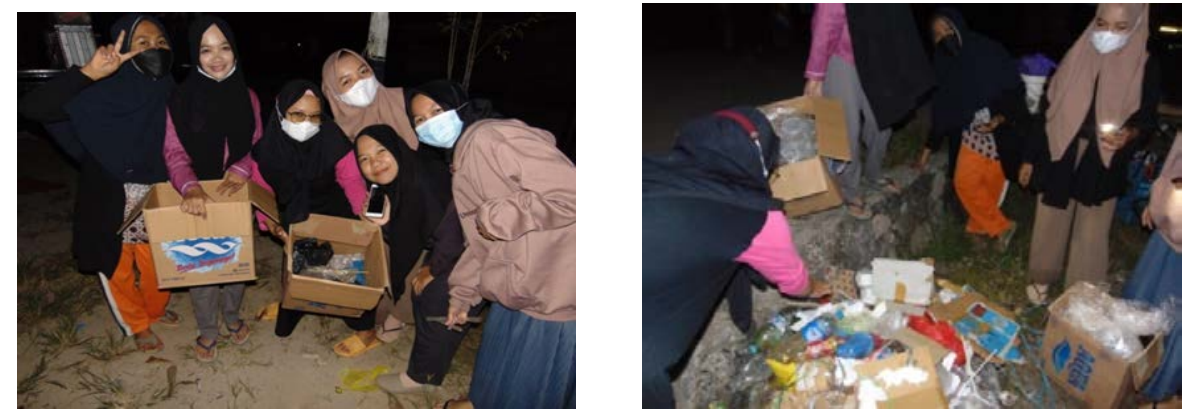

Gambar 2. Proses Pengumpulan Sampah Plastik yang Berada di Pinggir Jalan

3. Sediakan tongkat panjang, Sebelum memasukkan sampah plastik ke dalam botol. Tongkat Panjang tersebut akan digunakan untuk mendorong sampah plastik supaya muat dimasukkan di dalam botol.

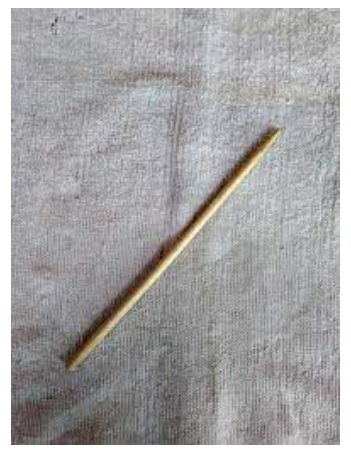

Gambar 3. Contoh tongkat panjang yang digunakan

4. Setelah bahan yang dibutuhkan semua sudah tersedia, maka kini saatnya sampah-sampah paltik yang sudah dibersihkan tersebut dimasukan kedalam botol bekas. setelah itu sampah plastik perlu dipotong kecil-kecil menggunakan gunting supaya mengahasilkan ecobrick yang cantik tampilannya. 


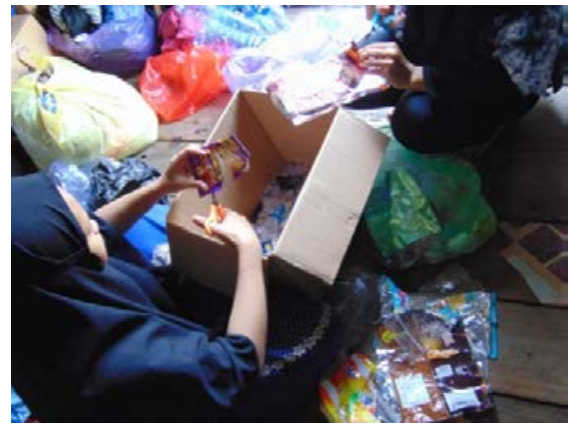

a. Proses Pemotongan Sampah Plastik

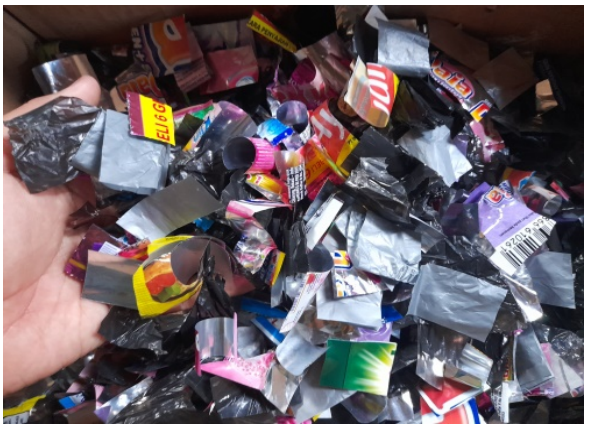

b. Sampah plastik yang sudah di potong kecil-kecil

Gambar 4. Proses Pemotongan Sampah Plastik Menjadi Potongan Kecil-Kecil

5. Ketika botol sudah terisi dengan sampah plastik yang sudah terpotong kecil-kecil, maka gunakan tongkat untuk mendorong sampah plastik agar padat di dalam botol. Apabila tersisa ruangan tempat udara didalam botol, isilah sampai tidak tersisa ruangan udara dengan mendorong kembali sampah plastik tersebut mennggukan tongkat.

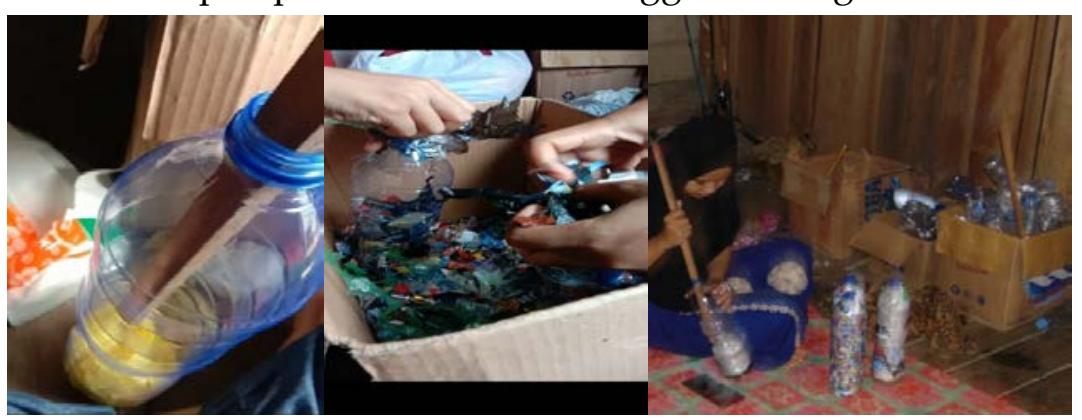

Gambar 5. Proses Memasukkan Potongan Sampah Ke Dalam Botol

6. Botol yang sudah diisi sampah plastik harus ditimbang agar menghasilkan bata yang berkualitas. Berat standar 200 Gram perbotol adalah berat standar ecobrick botol air mineral ukuran 600 ML. sedangkan botol air menralyang ukuran 1,5 Liter beratnya ialah 500 gram.

7. Kemasan-kemasan plastik yang sudah diisi hingga padat semuannya digabungkan dan disusun menjadi benda-benda yang bermanfaat seperti meja, kursi, atau bangku, dan dinding serta lantai panggung juga banyak lagi lainnya yang bisa dibuat untuk menjadi benda yang berguna serta bermanfaat.

8. Botol-botol ecobrick direkatkan menggunakan lem adhesive atau bahan-bahan gibs/semen agar Ecobrick dapat menempel dengan baik maka botol-botol itu harus diikat menggunakan tali dengan kuat.
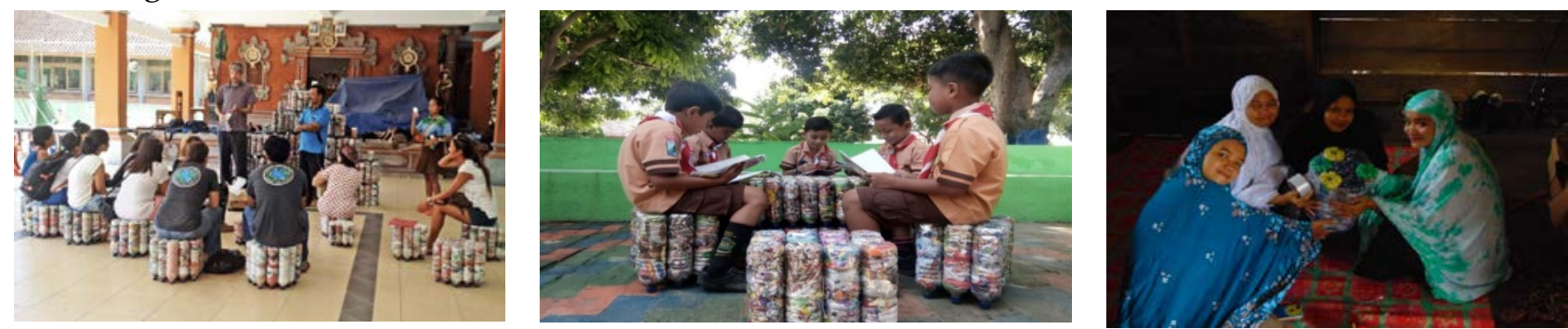

Gambar 6. Hasil produk ecobrick 
Gerakkan pemanfaatan sampah dengan metode ecobrick di Indonesia mulai berkembang dengan baik. Berbagai komunitas yang ada dalam masyarakat dan anak sekolah dari usia anakanak sampai dewasa dapat membuat ecobrick (Istiqomah et al., 2019). Terdapat banyak contoh kelompok-kelompok masyarakat yang ada di Indonesia yang telah membuat ecobrick yang mana kemudian dibentuk menjadi berbagai benda yang dapat digunakan sehari-hari (Ohee \& Keiluhu, 2020). Dalam hal ini kelompok anak-anak, pemuda dan dewasa yang berada di Desa Luwuk Kanan dapat melakukan kegiatan pembuatan ecobrick untuk memanfaatkan limbah sampah plastik yang berada di lingkungan dan di jadikan suatu produk yang bernilai ekonomis yang bisa dimanfaatkan untuk kebutuhan sehari-hari, seperti bangku/kursi, meja dan lain-lain sebagainya. Dengan membuat ecobrick kita dapat mengurangi sampah yang sering mengotori sungai dan juga berbahaya bagi kehidupan makhluk hidup di sungai. Adapun metode tersebut dapat mengurangi sampah plastik yang biasanya di bakar oleh masyarakat sekitar.

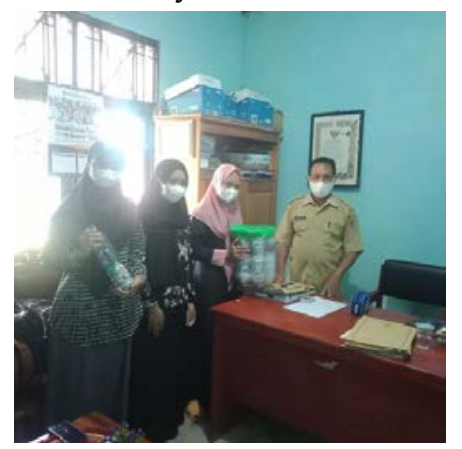

Gambar 7. Penyerahan produk ecobrick ke kepala Desa Luwuk Kanan

\section{KESIMPULAN}

Pelaksanaan Program pengabdian pengelolaan sampah di desa Luwuk Kanan dapat dikatakan berhasil dan bisa diterima dengan baik oleh perangkat desa Luwuk Kanan, pelakasanaan Program pengabdian ini juga dimaksudkan agar warga bisa memanfaatkan sampah untuk menghasilkan barang-barang yang bernilai ekonomis. Penanggulangan sampah dengan metode ecobrick termasuk salah satu metode yang baru diperkenalkan dan digunakan oleh masyarakat desa Luwuk Kanan, biasanya masyarakat setempat hanya memusnahkan sampah dengan cara dibuang ke sungai ataupun di bakar, dengan diperkenalkannya metode ecobrik kini masyarakat dapat mengolah sampah menjadi bahan yang bernilai ekonomis dan tentu ramah lingkungan.

\section{DAFTAR PUSTAKA}

Andriastuti, B. T., Arifin, A., \& Fitria, L. (2019). Potensi Ecobrick dalam Mengurangi Sampah Plastik Rumah Tangga di Kecamatan Pontianak Barat. Jurnal Teknologi Lingkungan Lahan Basah, 7(2), 055. https://doi.org/10.26418/jtllb.v7i2.36141

Fauzi, M., Efizon, D., Sumiarsih, E., Windarti, W., Rusliadi, R., Putra, I., \& Amin, B. (2019). Pengenalan dan pemahaman bahaya pencemaran limbah plastik pada perairan di Kampung Sungai Kayu Ara Kabupaten Siak. Unri Conference Series: Community Engagement, 1, 341-346. https://doi.org/10.31258/unricsce.1.341-346

Ikhsan, M., \& Tonra, W. S. (2021). Pengenalan Ecobrick di Sekolah Sebagai Upaya Penanggulangan Masalah Sampah. PATIKALA: Jurnal Pengabdian Kepada Masyarakat, 1(1), 32-38. 
https://doi.org/10.51574/patikala.v1i1.95

Indaraswati, D. (2017). Pengemasan makanan. Forum Ilmu Kesehatan.

Istiqomah, A. N., Sudaryanto, S., \& Iswanto. (2019). Model Reward System Dalam Praktik Ecobrick Pada Siswa Sdn Sindurejan Dan Sdn Tamansari I Kota Yogyakarta.

Istirokhatun, T., \& Nugraha, W. D. (2019). Pelatihan Pembuatan Ecobricks sebagai Pengelolaan Sampah Plastik di Rt 01 Rw 05, Kelurahan Kramas, Kecamatan Tembalang, Semarang. Jurnal Pasopati "Pengabdian Masyarakat Dan Inovasi Pengembangan Teknologi," 1(2), 85-90.

Jambeck, J. R., R. Geyer, C., Wilcox, T. R., Siegler, M., Perryman, A., Andrady, R., Narayan, \& Law, K. L. (2015). Plastic waste inputs from land into the ocean. Scienc, 347, 768-771.

Nufus, H., \& Zuriat, Z. (2020). Sosialisasi Dampak Pencemaran Plastik Terhadap Biota Laut Kepada Masyarakat Di Pantai Lhok Bubon Aceh Barat. Jurnal Marine Kreatif, 3(2), 7-13. https://doi.org/10.35308/jmk.v3i2.2286

Nuruzzaman, W. P. (2021). Ecobrick Sebagai Solusi Penanggulangan Sampah Non-Organik Rumah Tangga di Lingkungan Sayo Baru. Jurnal Pengabdian Magister Pendidikan IPA, 4(2), 05. https://doi.org/10.29303/jpmpi.v4i2.730

Ohee, H. L., \& Keiluhu, H. J. (2020). Pemanfaatan Limbah Plastik Menjadi Ecobricks Di Kampung Ayapo, Kabupaten Jayapura, Papua. VIVABIO: Jurnal Pengabdian Multidisiplin, 2(3), 31. https://doi.org/10.35799/vivabio.2.3.2020.31239

Palupi, W., Wahyuningsih, S., Widiyastuti, E., Nurjanah, N. E., \& Pudyaningtyas, A. R. (2020). Pemanfaatan Ecobricks Sebagai Media Pembelajaran Untuk Anak Usia Dini. DEDIKASI: Community Service Reports, 2(1), 28-34. https://doi.org/10.20961/dedikasi.v2i1.37624

Purwaningrum, P. (2016). Upaya Mengurangi Timbulan Sampah Plastik Di Lingkungan. Indonesian Journal of Urban and Environmental Technology, 8(2), 141. https://doi.org/10.25105/urbanenvirotech.v8i2.1421

Putra, H. P., \& Yuriandala, Y. (2010). Studi Pemanfaatan Sampah Plastik Menjadi Produk dan Jasa Kreatif. Jurnal Sains ETeknologi Lingkungan, 2(1), 21-31. https://doi.org/10.20885/jstl.vol2.iss1.art3

Rahayu, A. Y. (2021). Sistem Peningkatan Life Skills Santri Di Pondok Program Studi Pendidikan Agama Islam. In Skripsi. IAIN Purwokerto.

Rosita, T., \& Mintarsih, E. (2021). Penyuluhan Pengolahan Sampah Rumah Tangga Secara Daring Melalui Metode Takakura oleh Kelompok Wanita Tani Kebun Sauyunan. Abdimas Siliwangi, 4(2), 227-232. https://doi.org/10.22460/as.v4i2p\%25p.6704

Sumastuti, E., Setyorini, N., \& Gultom, H. C. (2018). Ecobrick sebagai Solusi Pengelolaan Limbah Plastik di Kelurahan Bendan Ngisor Kecamatan Gajahmungkur Kota Semarang. Proceeding SNK-PPM, 1, 1-5.

Zuhri, T. S., Cahyanti, E. T., Alifa, E. frida akmalia, \& Asyfiradayati, R. (2020). Daur Ulang Limbah Sampah melalui Metode Ecobrick di Desa Jatisari, Kecamatan Sambi, Kabupaten Boyolali. Proceeding of The 11th University Research Colloquium 2020: Bidang Sains Dan Teknologi, 30. 